\title{
Health concerns regarding the effect of the COVID-19 pandemic on male fertility
}

\author{
Hamidreza Mosleh ${ }^{1}$, Fatemeh Moradi ${ }^{1}$, Mehdi Mehdizadeh$^{1}$, Marziyeh Ajdary $^{2}$, Alaa Moeinzadeh${ }^{1}$, Ronak Shabani $^{1}$ \\ ${ }^{1}$ Department of Anatomical Sciences, Faculty of Medicine and ${ }^{2}$ Endometriosis Research Center, Iran University of Medical Sciences, Tehran, Iran
}

Severe acute respiratory syndrome coronavirus 2 (SARS-CoV-2) is a novel coronavirus found in China in 2019. The disease caused by SARSCoV-2, coronavirus disease 2019 (COVID-19), has been found to be closely related to the cells that secrete angiotensin-converting enzyme 2 (ACE2). ACE2 is involved in the renin-angiotensin system and is widely secreted in several tissues, including the testis, which has raised concerns because organs with high expression of the ACE2 receptor are susceptible to infection. Analyses have shown that in testicular cells, such as spermatogonia, seminiferous duct cells, Sertoli cells, and Leydig cells, there is a high expression level of ACE2. Therefore, SARS-CoV-2 may damage male reproductive tissues and cause infertility. Since male infertility is an important problem, scientists are evaluating whether COVID-19 may influence male infertility through the ACE2 receptor.

Keywords: COVID-19; Male fertility; Pandemic

\section{Introduction}

In late 2019, a novel coronavirus, known as severe acute respiratory syndrome coronavirus 2 (SARS-CoV-2), was found in China [1]. Shortly thereafter, the World Health Organization (WHO) has prolonged its classification of the coronavirus disease 2019 (COVID-19) outbreak as the highest level of a worldwide pandemic [2]. SARSCoV-2 is a novel type of coronavirus that causes disease in humans. Severe acute respiratory syndrome (SARS-CoV, also now sometimes referred to as SARS-CoV-1) and Middle East respiratory syndrome coronavirus (MERS-CoV) are other members of this virus family, outbreaks of which occurred in 2003 and 2013, respectively [3].

Effects of COVID-19 on some systems other than the lungs (e.g., the gastrointestinal and cardiovascular systems) have been detected [4]. The potential impact of COVID-19 on the male reproductive sys-

Received: January 24, $2021 \cdot$ Accepted: February 22, 2021 Corresponding author: Ronak Shabani

Department of Anatomical Sciences, Faculty of Medicine, Iran University of Medical Sciences, Shahid Hemmat Highway, Tehran 1449614535, Iran Tel: +98-9128362550 Fax: +98-2188622689 E-mail: Shabani.r@iums.ac.ir

This is an Open Access article distributed under the terms of the Creative Commons Attribution Non-Commercial License (http://creativecommons.org/licenses/by-nc/4.0/) which permits unrestricted non-commercial use, distribution, and reproduction in any medium, provided the original work is properly cited. tem has also been discussed. Important data have shown that the reproductive organs in men are susceptible to attack by hepatitis $B$ virus, hepatitis $C$ virus, human immunodeficiency virus (HIV), and human papillomavirus [5]. Viruses can impact and gain entry to the male reproductive system both directly and indirectly [6]. Recent studies have documented the function of the angiotensin-converting enzyme 2 (ACE2) receptor as a gate that allows SARS-CoV-2 to enter into cells into the male reproductive tract [7]. ACE2 receptors facilitate infection by coronaviruses [8]. ACE2 is a zinc metalloprotease [9] that is expressed in some organs, such as the lung and testis [10]. Although previous studies have reported limited informationon the relationship of coronavirus diseases with reproductive function, the latest research on the pathophysiological features of SARS-CoV-2 underscores the need to determine whether COVID-19 can influence male infertility [2].

Infertility represents the most serious reproductive disorder [11]. According to the definition of the $\mathrm{WHO}$, infertility is a reproductive system disease that causes disability and affects more than 50 million couples throughout the world [12]. In light of concerns in the field of reproductive medicine, doctors and patients are examining the most appropriate methods to face the challenges that lie ahead [12]. COVID-19 has distinctive effects between the sexes, and the question of why men are more strongly affected by COVID-19 than 
women remains to be elucidated [13]. The numerous health concerns associated with COVID-19 pose an intrinsic danger to the reproductive system [14]. Since infertility in men is a global problem with potential implications for the survival of the human race, it is important to evaluate exactly how the COVID-19 pandemic affects male infertility.

\section{SARS-CoV-2 cellular pathways}

SARS-CoV-2 is genetically closer to bat-originated SARS-like coronaviruses, which include bat SARS-like coronavirus isolate (bat-SLCoV-ZC-45) and bat-SL-CoV-ZXC-21 (approximately 88\% genomic similarity, than to SARS-CoV-1 (approximately 79\%) and MERS-CoV (approximately 50\%). However, homology modeling has shown that SARS-CoV-2 has the same receptor binding field organization as that of SARS-CoV-1, indicating that SARS-CoV-2 could have a similar pathogenesis to that of SARS-CoV-1 [15].

The coronavirus family includes large enveloped viruses with and single-stranded RNA genomes (roughly 32 kilobases) [16]. These RNA viruses are covered by a coating [17]. This coating includes three different proteins: an envelope protein, a membrane protein, which plays a role in viral assembly; and a spike protein, which facilitates entry of the virus into its target. The coronavirus spike protein includes two unique subunits (S1 and S2) that assist viral-host attachment (Figure. 1). The S1 domain plays roles in adhering to the membrane of the target cell. Several receptors on the human cell membrane are involved in $\mathrm{S} 1$ attachment have been recognized, such as the ACE2 receptor. The function of the S2 domain is to merge the host and viral cell membranes, permitting the SARS-CoV-2 genome to enter the target cell [18].

\section{Role of ACE2 in COVID-19 Infection}

Early reports recognized that SARS-CoV-1and SARS-CoV-2 are associated with cells that express the ACE2 receptor on their outer surface, and that the ACE2 receptor is an efficient target for these two coronaviruses [2]. ACE2 is a zinc metalloprotease, the gene of which is located on Xp22.2. It is a protein with 805 amino acids that belongs to the category of dipeptidyl carboxypeptidases. ACE2 includes an $\mathrm{N}$-terminal 17-amino-acid signal peptide and a C-terminal 22-amino-acid membrane anchor. Additionally, it has a preserved motif at the zinc metalloprotease consensus sequence (HEXXH) and a preserved glutamine residue at Glu402 that functions as the third zinc ligand [9].

ACE2 can hydrolyze angiotensin I to make angiotensin 1-9 and cleaves angiotensin II to form angiotensin 1-7 [9,19]. Angiotensin II exerts damaging effects on tissues by angiotensin II type $1\left(\mathrm{AT}_{1}\right)$ re-

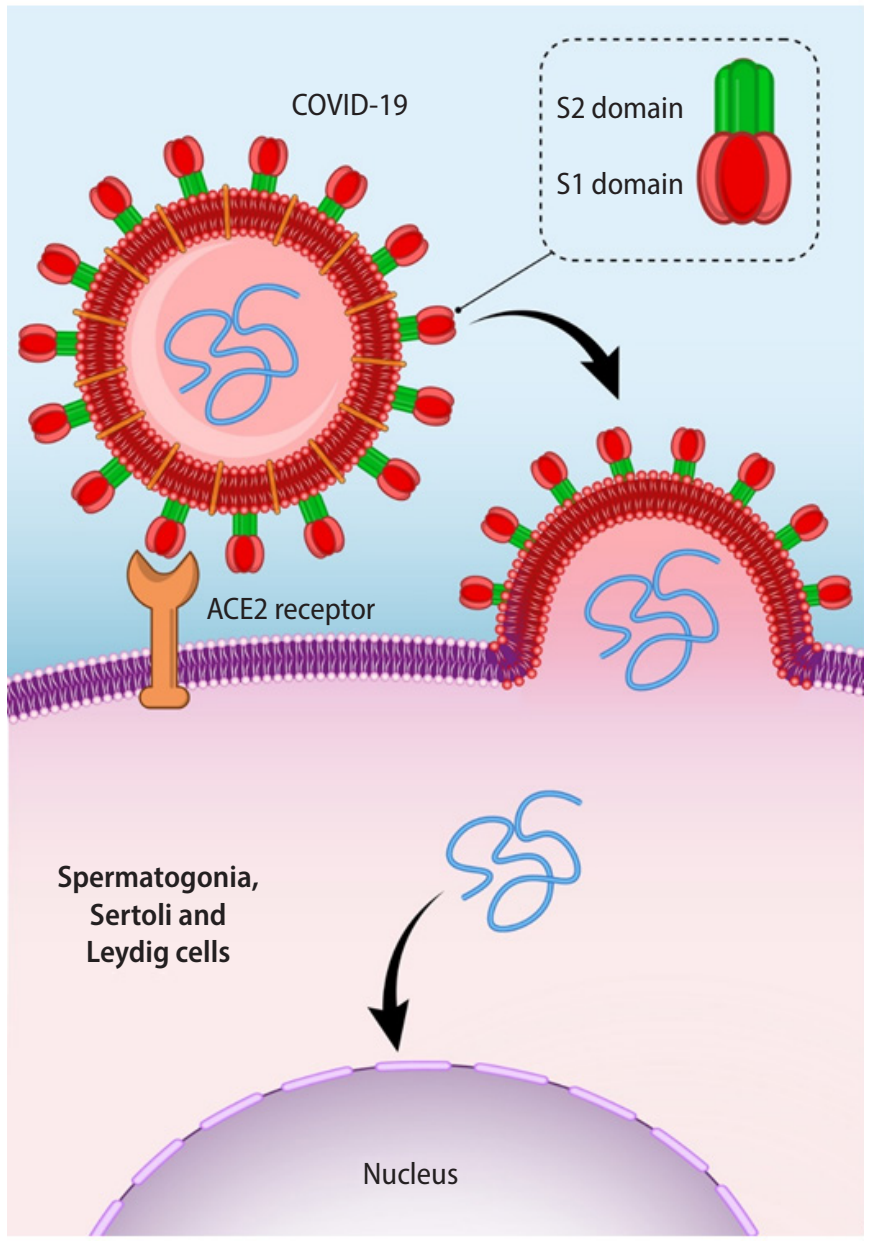

Figure 1. Subunits of coronaviruses and their role in viral access to cells in the male reproductive tract. ACE2, angiotensin-converting enzyme 2.

ceptors, whereas the angiotensin 1-7-MAS receptor axis induces beneficial stability and favorable functions, including vasodilatory, antifibrotic, and anti-inflammatory effects, in various tissues. ACE2 is widely expressed in numerous organs, such as the lung, intestine, liver, heart, kidney, and testis [10]. It has been reported that ACE2 plays a relevant regulatory role, including the facilitation of cell death by 5 hydroxytryptamine receptor $3 \mathrm{~A}$ through tumor necrosis factor alpha secretion as a result of increased serotonin expression. Furthermore, cholinergic receptor nicotinic alpha 1 is involved in inflammation induced by leukocytes. Therefore, it is expected that SARS-CoV-2, as a novel coronavirus, will have intrinsically negative effects on humans [20].

COVID-19 attaches to the ACE2 receptor more powerfully than other SARS viruses, enhancing its pathogenicity and capability for person-to-person transfer [10]. ACE2 receptor detection occurs in the initial phase of virus invasion; therefore, ACE2 receptor expression could be a main factor of tissue and host cell tropism and pathoge- 
nicity following duplication of the virus [21]. The virus enters cells through the ACE2 receptor. In theory, tissues that overexpress ACE2 are less resistant to infection [22]. Paradoxically, compared with other organs, the lungs have very low expression of ACE2, which is involved in the renin-angiotensin system (RAS). ACE2 antagonizes the initiation of the typical RAS and defends against tissue injury [23]. Similarly to the circulating RAS, the local RAS plays a critical function in the physiology of numerous organs, including the testes [2].

ACE2 receptors have an important function in the pathogenesis of COVID-19; therefore, cells that express high levels of the ACE2 receptor can be inherently targeted and damaged by the virus [8]. In the study conducted by Fu et al. [24], the mRNA expression of the ACE2 gene in humans was investigated using RNA-sequencing. The number of reads per kilobase of transcript per million mapped reads counts of ACE2 release of the lung was 0.345 , while it was 26.895 in the testes.

\section{Impact of coronaviruses on the male reproductive system via ACE2}

The most important part of the male reproductive system is the testis [25]. The blood-testis barrier and blood-epididymis barrier are critical physical blockades in the male reproductive system, but ACE2 receptors help SARS-CoV-2 infiltrate these barriers, leading to testicular dysfunction [26]. Immunohistochemical evaluations of ACE2 antibodies in healthy testes showed that ACE2 is present at extremely high levels in Leydig and seminiferous duct cells, but at very small (or nonexistent amounts) in other tissues in the male reproductive tract, such as the seminal vesicles, ductus deferens, epididymis, and prostate. Excessive ACE2 secretion in the testis shows that SARS-CoV-2 does not just infect the lung, but could also affect other organs such as the testis, potentially disrupting puberty in young boys and causing infertility in adult men [24]. In 2016, Xu et al. [27] detected orchitis in cadavers of the patients infected by SARS-CoV-1.

Several analyses discovered that in testicular cells, there is a high expression level of ACE2, mostly in spermatogonia, seminiferous duct cells, Sertoli, and Leydig cells. In comparison with other organs, the testis displays the highest level of ACE2 mRNA and protein expression; therefore, it may serve as an innate host for SARS-CoV-2 [8]. Wang and $\mathrm{Xu}$ [7] studied the ACE2 gene expression pattern in mature male testes at the level of single-cell transcriptomes. The outcomes showed that ACE2 expression was markedly enhanced in spermatogonia, Leydig cells, and Sertoli cells. A gene ontology study reported that genes related to transmission and reproduction of SARS-CoV-2 were very strongly enhanced in ACE2-positive spermatogonia; however, genes related to gamete generation had little appearance. Liu et al. [28] concluded that the somatic cells in the tes- tis might be more susceptible than germ cells for attack by COVID-19; this was especially true for Sertoli cells, because they expressed ACE2 more than $90 \%$. As an additional examination of the role of ACE2 in testis tissue, they evaluated highly expressed genes and then concentrated on the utility of these genes, which were found to be related to reactive oxygen species in metabolic processes, cellular responses to stress, cohesion to the host cell, activation of leukocytes in the immune response, cell growth arrest, and homeostasis [28].

Illiano et al. [23] made two hypotheses. The first hypothesis was that the virus could enter the testis tissue and alter its function. The second hypothesis was that virus-ACE2 receptor binding leads to increased expression of ACE2 and also increases inflammatory feedback. Inflammatory cells can affect Sertoli and Leydig cells functionally. As a result of damage to male genital tissues by the virus, spermatogenesis might be disturbed, which could pose a risk for male fertility [8].

The first role of Leydig cells is to make sex steroid hormones, especially testosterone. The existence of MAS receptors might imply that angiotensin (1-7) moderates the production of testosterone. In a recent study, SARS-CoV-2 RNA was not detected in the semen and tissue samples by testicular biopsy. These outcomes could show that the virus does not directly infect the testes or male genital tract even in the acute stage. Inflammatory cells could affect the role of Leydig cells, thereby inhibiting testosterone production and destroying the cells of seminiferous ducts [23]. Ma et al. [29] reported that in males with COVID-19, luteinizing hormone (LH) was significantly raised, but the ratio of follicle-stimulating hormone to $\mathrm{LH}$ and the ratio of testosterone to $\mathrm{LH}$ were dramatically reduced. It is very interesting that the testicular expression of ACE2 is associated with age. Older men are therefore at a lower risk of testicular attack by SARS-CoV-2 than younger men [20].

Clinical examinations found angiotensin 1-7-MAS receptors in the seminiferous ducts and interstitial region, mainly Leydig cells, in healthy men. However, neither mechanism of the RAS was detected in the seminiferous ducts of infertile men who had nonobstructive azoospermia [10]. Shen et al. [20] found that testis ACE2 expression was higher in infertile men than in healthy men, suggesting that SARS-CoV-2 may lead to reproductive disorders by irregular activation of the ACE2 pathway. They found that 30-year-old and 60-yearold men had the highest and lowest expression of ACE2 in the testis, respectively.

Recent research on nonobstructive azoospermia patients showed that MAS and ACE2 had low mRNA expression levels, which might furnish additional evidence that these genes are associated with infertility in men [30]. Furthermore, COVID-19 infection might increase sperm DNA fragmentation through the activation of pathogenic pathways, which, in turn, can disturb fertilizing potential [31]. 


\section{Conclusion}

Theoretically, there is a possibility of damage to the male reproductive system and, consequently, infertility after COVID-19 infection. The pattern of SARS-CoV-2 infection within testicular tissue has yet to be clarified. However, outcomes from other members of the coronavirus family, especially SARS-CoV-1, provide useful insights into tissue-specific viral pathophysiology. To date, there is no evidence regarding whether SARS-CoV-2 uses ACE2 in the genital tissues and what, or any effect, it has in male infertility. Unfortunately, primary examinations have many limitations (e.g., examination techniques, small sample size, and the progress of the viral infection). More analyses are necessary to clarify the consequences of COVID-19 for male fertility and to investigate ways of preventing reproductive system damage and/or treating such damage. Additional research on this topic should be conducted as soon as possible.

\section{Conflict of interest}

No potential conflict of interest relevant to this article was reported.

\section{ORCID}

Hamidreza Mosleh
Fatemeh Moradi
Mehdi Mehdizadeh
Marziyeh Ajdary
Alaa Moeinzadeh
Ronak Shabani

https://orcid.org/0000-0003-0388-4158 https://orcid.org/0000-0001-9231-280X https://orcid.org/0000-0002-9268-7318 https://orcid.org/0000-0002-4154-7788 https://orcid.org/0000-0002-0262-5501 https://orcid.org/0000-0003-3075-6071

\section{Author contributions}

Conceptualization: RS, FM. Data curation: HM, AM. Writing-original draft: HM. Writing-review \& editing: MA, MM.

\section{References}

1. Witherspoon L, Fitzpatrick R, Patel P, Flannigan R, Roberts MT, Krakowsky $Y$, et al. Clinical pearls to managing men's health conditions during the COVID-19 pandemic. Can Urol Assoc J 2020;14: E161-6.

2. Cavalcante MB, Sarno M, da Silva AC, Araujo Junior E, Barini R. Is there any possible link between COVID-19 and human infertility? J Matern Fetal Neonatal Med 2020;1-2.

3. Wang Y, Wang Y, Chen Y, Qin Q. Unique epidemiological and clinical features of the emerging 2019 novel coronavirus pneumonia
(COVID-19) implicate special control measures. J Med Virol 2020;92:568-76.

4. Li H, Xiao X, Zhang J, Zafar MI, Wu C, Long Y, et al. Impaired spermatogenesis in COVID-19 patients. EClinicalMedicine 2020;28: 100604

5. Le Tortorec A, Matusali G, Mahe D, Aubry F, Mazaud-Guittot S, Houzet $L$, et al. From ancient to emerging infections: the odyssey of viruses in the male genital tract. Physiol Rev 2020;100:1349_ 1414.

6. Fijak M, Pilatz A, Hedger MP, Nicolas N, Bhushan S, Michel V, et al. Infectious, inflammatory and 'autoimmune' male factor infertility: how do rodent models inform clinical practice? Hum Reprod Update $2018 ; 24: 416-41$

7. Wang Z, Xu X. scRNA-seq profiling of human testes reveals the presence of the ACE2 receptor, a target for SARS-CoV-2 infection in spermatogonia, Leydig and Sertoli cells. Cells 2020;9:920.

8. Abobaker A, Raba AA. Does COVID-19 affect male fertility? World J Urol 2021;39:975-6.

9. Donoghue M, Hsieh F, Baronas E, Godbout K, Gosselin M, Stagliano $\mathrm{N}$, et al. A novel angiotensin-converting enzyme-related carboxypeptidase (ACE2) converts angiotensin I to angiotensin 1-9. Circ Res 2000;87:E1-9.

10. Younis JS, Abassi Z, Skorecki K. Is there an impact of the COVID-19 pandemic on male fertility? The ACE2 connection. Am J Physiol Endocrinol Metab 2020;318:E878-80.

11. Guo J, Grow EJ, Mlcochova H, Maher GJ, Lindskog C, Nie X, et al. The adult human testis transcriptional cell atlas. Cell Res 2018; 28:1141-57.

12. Geber S, Prates N, Sampaio M, Valle M, Meseguer M. COVID-19 should be a novel indication for fertility preservation. JBRA Assist Reprod 2020;24:233-4.

13. Fan C, Lu W, Li K, Ding Y, Wang J. ACE2 expression in kidney and testis may cause kidney and testis infection in COVID-19 patients. Front Med (Lausanne) 2021;7:563893.

14. Perry MJ, Arrington S, Neumann LM, Carrell D, Mores CN. It is currently unknown whether SARS-CoV-2 is viable in semen or whether COVID-19 damages spermatozoa. Andrology 2021;9:302.

15. Qiao J. What are the risks of COVID-19 infection in pregnant women? Lancet 2020;395:760-2.

16. Ortega JT, Serrano ML, Pujol FH, Rangel HR. Role of changes in SARS-CoV-2 spike protein in the interaction with the human ACE2 receptor: an in silico analysis. EXCLI J 2020;19:410-7.

17. Li F. Structure, function, and evolution of coronavirus spike proteins. Annu Rev Virol 2016;3:237-61.

18. Segars J, Katler Q, McQueen DB, Kotlyar A, Glenn T, Knight Z, et al. Prior and novel coronaviruses, coronavirus disease 2019 (COVID-19), 
and human reproduction: what is known? Fertil Steril 2020;113: $1140-9$.

19. Jing Y, Run-Qian L, Hao-Ran W, Hao-Ran C, Ya-Bin L, Yang G, et al. Potential influence of COVID-19/ACE2 on the female reproductive system. Mol Hum Reprod 2020;26:367-73.

20. Shen Q, Xiao X, Aierken A, Yue W, Wu X, Liao M, et al. The ACE2 expression in Sertoli cells and germ cells may cause male reproductive disorder after SARS-CoV-2 infection. J Cell Mol Med 2020;24: 9472-7.

21. Zhang H, Penninger JM, Li Y, Zhong N, Slutsky AS. Angiotensin-converting enzyme 2 (ACE2) as a SARS-CoV-2 receptor: molecular mechanisms and potential therapeutic target. Intensive Care Med 2020;46:586-90.

22. Li R, Yin T, Fang F, Li Q, Chen J, Wang Y, et al. Potential risks of SARSCoV-2 infection on reproductive health. Reprod Biomed Online 2020;41:89-95.

23. Illiano E, Trama F, Costantini E. Could COVID-19 have an impact on male fertility? Andrologia 2020;52:e13654.

24. Fu J, Zhou B, Zhang L, Balaji KS, Wei C, Liu X, et al. Expressions and significances of the angiotensin-converting enzyme 2 gene, the receptor of SARS-CoV-2 for COVID-19. Mol Biol Rep 2020;47: 4383-92.

25. Douglas GC, O'Bryan MK, Hedger MP, Lee DK, Yarski MA, Smith Al, et al. The novel angiotensin-converting enzyme (ACE) homolog,
ACE2, is selectively expressed by adult Leydig cells of the testis. Endocrinology 2004;145:4703-11.

26. Olaniyan OT, Dare A, Okotie GE, Adetunji CO, Ibitoye BO, Bamidele OJ, et al. Testis and blood-testis barrier in Covid-19 infestation: role of angiotensin-converting enzyme 2 in male infertility. J Basic Clin Physiol Pharmacol 2020;31:20200156.

27. Xu J, Qi L, Chi X, Yang J, Wei X, Gong E, et al. Orchitis: a complication of severe acute respiratory syndrome (SARS). Biol Reprod 2006;74:410-6.

28. Liu X, Chen Y, Tang W, Zhang L, Chen W, Yan Z, et al. Single-cell transcriptome analysis of the novel coronavirus (SARS-CoV-2) associated gene ACE2 expression in normal and non-obstructive azoospermia (NOA) human male testes. Sci China Life Sci 2020; 63:1006-15.

29. Ma L, Xie W, Li D, Shi L, Mao Y, Xiong Y, et al. Effect of SARS-CoV-2 infection upon male gonadal function: a single center-based study. MedRxiv 20037267 [Preprint]. 2020 [cited 2021 May 5]. Available from: https://doi.org/ 10.1101/2020.03.21.20037267.

30. Reis AB, Araujo FC, Pereira VM, Dos Reis AM, Santos RA, Reis FM. Angiotensin (1-7) and its receptor Mas are expressed in the human testis: implications for male infertility. J Mol Histol 2010;41: 75-80.

31. Anifandis G, Messini Cl, Daponte A, Messinis IE. COVID-19 and fertility: a virtual reality. Reprod Biomed Online 2020;41:157-9. 